\title{
Tatuagem e autonomia: reflexões sobre a juventude
}

\section{Andréa Osório}

\begin{abstract}
resumo Pesquisa realizada em dois estúdios de tatuagem da cidade do Rio de Janeiro apontou para a predominância da prática na faixa etária dos 20 aos 29 anos. Cerca de $60 \%$ do público de um dos estúdios é formado por jovens entre 16 e 29 anos. Por trás da sedução que a tatuagem exerce sobre a juventude, parece estar um processo de marcação social - sobre o corpo - de autonomia pessoal, que foi nomeado na literatura dedicada ao estudo da tatuagem contemporânea como posse de si, conceito que remete à emergência de um processo de individualizaçáo, em que a tatuagem pode se apresentar como signo propício a uma prova pessoal (e social) de força e coragem ou como epíteto de uma rebelião silenciosa contra instâncias de controle do indivíduo, sobretudo a família.
\end{abstract}

palavras-chave Tatuagem. Juventude. Autonomia.

"Menino do Rio Calor que provoca arrepio Dragão tatuado no braço Calção, corpo aberto no espaço"

Caetano Veloso

\section{Introdução}

Quando Petit, o "Menino do Rio" que Caetano Veloso cantou em versos, fez sua aparição na Praia de Ipanema com o célebre "dragáo tatuado no braço", ele náo foi o primeiro de sua geração a associar surf e juventude ao uso de tatuagens (Marques 1997). Contudo, foi um pioneiro e serviu de ícone na difusão da prática tanto entre jovens quanto entre as camadas médias cariocas. A partir de Petit e da cultura de massas, construiu-se um imaginário ligando a tatuagem à juventude no país. Além dos surfistas, outros grupos jovens, como os punks do ABC paulista, fizeram uso da marca (Marques 1997).

Em observação de campo em dois estúdios de tatuagem na cidade do Rio de Janeiro entre 2003 e 2004, percebi que os grupos de cultura jovem não formam a maioria da clientela. Em um dos estúdios pesquisados, próximo às praias de Copacabana e Ipanema, os surfistas são um grupo visível entre os clientes, mas não constituem o público majoritário. Por outro lado, o mesmo imaginário que associa a prática a estes grupos, normalmente associa-a a um universo masculino e os próprios grupos jovens sáo pensados como fundamentalmente masculinos ${ }^{1}$ ou sem maiores reflexóes a partir do recorte de gênero, como por exemplo em Vianna (1985) sobre o universo funk carioca, Caiafa (1988) sobre os punks cariocas, Costa (1993) sobre os "carecas" paulistas e Abramo (1994) sobre punks e darks. Em campo, identifiquei um público majoritariamente feminino e que náo podia ser associado a nenhum grupo jovem específico.

Analisando fichas de cadastro de clientes de um dos estúdios pesquisados, localizado no bairro da Tijuca, Zona Norte ${ }^{2}$ carioca, observou-se que as mulheres formam cerca de 70\% dos clientes, número observado por outros tatuadores em outros estúdios, como Emerson, tatuador da Rocinha ${ }^{3}$, que afirmou ao

1. Conforme também observado por Weller (2005).

2. Área da cidade de baixo poder aquisitivo, embora a Tijuca sobressaia aí como região de classe média.

3. Antiga "maior favela da América Latina", hoje com status de bairro, encravada no morro entre os bairros da Gávea e São Conrado, Zona Sul carioca, áreas extremamente valorizadas da cidade. 
site Beleza Pura ${ }^{4}$ que $70 \%$ de seus clientes são mulheres (Leal 2005). Estas fichas de cadastro apontaram, ainda, para faixas etárias dominantes no público local, outras que não aquelas consideradas “jovens”. Estes dados indicaram a necessidade de se repensar a tatuagem não mais como uma prática de juventude, mas como um processo de marcação corporal que tem atingido estratos populacionais que não estáo relacionados às culturas jovens.

Fonseca (2003), em levantamento quantitativo das fichas de cadastro de clientes ${ }^{5}$ de um estúdio pesquisado na cidade de Florianópolis, observou que as faixas etárias não-jovens sofreram um incremento e os homens deixaram de ser o público majoritário em função do crescimento da clientela feminina ${ }^{6}$. Quanto à mudança na faixa etária, o levantamento da autora demonstra que náo houve clientes acima dos 40 anos entre 1997 e 1998, situação que mudou paulatinamente a partir de 2000, ano em que já houve um cliente nesta faixa etária; em 2001, 7 clientes; em 2002, 12. A expressividade daqueles abaixo de 20 anos, por outro lado, caiu. Em 1997, eram 142 indivíduos, contra 135 dos 20 aos 39 anos. Em 2002, eram 90 abaixo dos 20 anos contra 235 acima, com uma super-representação da faixa de 20 a 24 anos: 113 indivíduos.

Há ainda muitos jovens que buscam a tatuagem como prática de modificação corporal. Entre os casos observados em campo, os recém-completos 18 anos são, muitas vezes, comemorados pela aquisiçáo da marca. Os 18 anos têm sido uma idade-limite, na medida

4. Ligado ao site do projeto Viva Favela do Viva Rio, ONG carioca. O projeto privilegia as comunidades de favelas e assim o faz também o Beleza Pura, mas voltado ao universo da estética.

5. Entre 1996 e 2002, exceto 1999.

6. O ano em que as mulheres se tornam maioria no estúdio pesquisado por Fonseca (2003) é 2000, mantendo-se maioria nos dois anos subseqüentes. em que uma Resolução Municipal impediu a prática para menores de 16 anos, e entre os 16 e 17 anos apenas com termo de responsabilidade assinado pelo responsável. Ainda assim, os estúdios pesquisados implementaram regras próprias, ainda mais rígidas: naquele pesquisado na Zona Sul, menores não são tatuados, enquanto no estúdio pesquisado na Zona Nor$\mathrm{te}^{7}$ o termo deve ser apresentado pelo próprio responsável.

Esta situação indica uma tutela por parte da família que é vista por alguns como incômoda. Parece ser a necessidade de romper com este status de menoridade, não no sentido jurídico, mas valorativo, que leva alguns a se tatuarem assim que os 18 anos chegam. Ou seja, a marca parece ser um indicativo de liberdade - aqui uma liberdade sobre o próprio corpo que se conjuga a uma liberdade por escolhas. Tratase de um processo análogo ao que se observou entre algumas mulheres de diversas faixas etárias em que a resistência da família, sobretudo nas figuras do pai e do marido, teve que ser enfrentada com afirmaçóes como "esse corpo é meu”, indicando náo apenas a necessidade de uma autonomia individual, mas a dificuldade de se adquirir/exercer esta autonomia.

\section{Perfil etário e de gênero}

O levantamento efetuado no cadastro de clientes do estúdio pesquisado na Tijuca $^{8}$, referente aos meses de setembro e dezembro de 2003 e janeiro de 2004, demonstrou uma varia-

7. Embora a comparação entre Zona Norte e Sul cariocas seja bastante presente na Antropologia Urbana brasileira, esta linha de análise não foi privilegiada no presente trabalho em função da baixa diferenciação observada entre os clientes dos dois estúdios pesquisados.

8. No estúdio pesquisado na Zona Sul, percebi que raramente os clientes preenchiam tais fichas, enquanto na Zona Norte nenhum cliente deixava de preenchê-las. Assim, não foi possível pesquisar o cadastro do estúdio observado na Zona Sul. 
Tabela n. 1-Faixa etária dos clientes do estúdio pesquisado na Zona Norte.

\begin{tabular}{|l|c|c|c|c|}
\hline \multirow{2}{*}{ FAIXA ETÁRIA } & \multicolumn{3}{|c|}{ MÊS/AN0 } & \multirow{2}{*}{ TOTAL } \\
\cline { 2 - 4 } & $\begin{array}{c}\text { SETEMBR0/ } \\
\mathbf{2 0 0 3}\end{array}$ & $\begin{array}{c}\text { DEZEMBR0/ } \\
\mathbf{2 0 0 3}\end{array}$ & $\begin{array}{c}\text { JANEIRO/ } \\
\mathbf{2 0 0 4}\end{array}$ & $11(2 \%)$ \\
\hline $16-17$ & $4(2.5 \%)$ & $6(2.4 \%)$ & $1(0.6 \%)$ & $38(6.6 \%)$ \\
\hline $18-19$ & $16(10 \%)$ & $10(4 \%)$ & $12(7.2 \%)$ & $181(31.3 \%)$ \\
\hline $20-25$ & $57(35.8 \%)$ & $78(30.7 \%)$ & $46(27.7 \%)$ & $98(17 \%)$ \\
\hline $26-29$ & $20(12.6 \%)$ & $49(19.3 \%)$ & $29(17.5 \%)$ & $175(30.2 \%)$ \\
\hline $30-39$ & $36(22.6 \%)$ & $87(34.2 \%)$ & $52(31.3 \%)$ & $58(10 \%)$ \\
\hline $40-49$ & $19(12 \%)$ & $17(6.7 \%)$ & $22(13.2 \%)$ & $13(2.2 \%)$ \\
\hline $50-59$ & $6(3.8 \%)$ & $4(1.6 \%)$ & $3(1.8 \%)$ & $4(0.7 \%)$ \\
\hline 60 ou mais & $1(0.6 \%)$ & $3(1.2 \%)$ & - & $579(100 \%)$ \\
\hline TOTAL & $159(100 \%)$ & $254(100 \%)$ & $166(100 \%)$ & \\
\hline
\end{tabular}

Gráfico n. 1 - Faixa etária dos clientes do estúdio pesquisado na Zona Norte, em números absolutos, nos meses pesquisados.

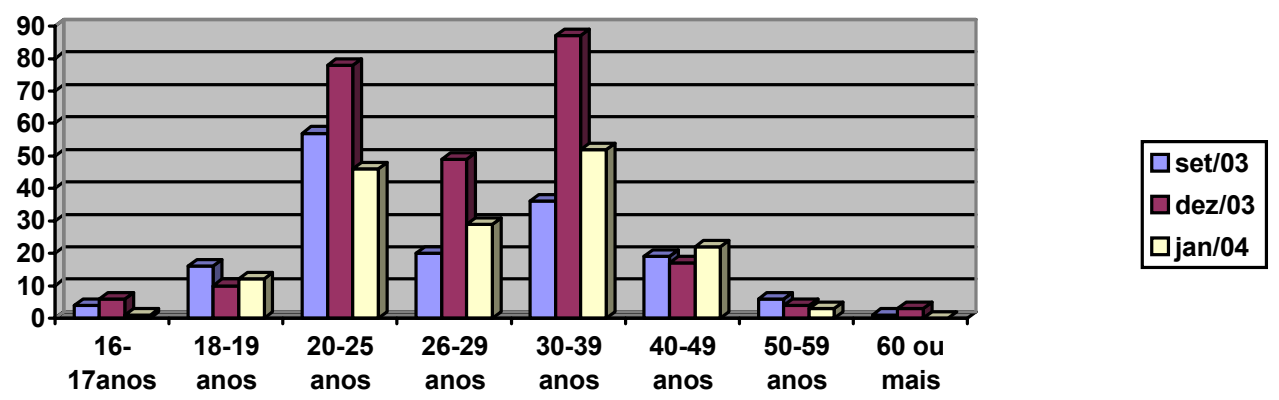

ção interessante quanto à faixa etária da clientela. Dezembro é considerado pelos tatuadores do estúdio um mês de alto movimento. Os meses do verão, os que o antecedem e o mês de julho são considerados mais proveitosos financeiramente? O total do mês de setembro foi de 159 respostas sobre idade em 162 fichas $^{10}$, enquanto o de dezembro foi de 254 em um total de 262 fichas e o de janeiro foi de 166 respostas em 180 fichas, conforme a tabela 1 e o gráfico 1 acima.

A construção de faixas etárias é, até certo ponto, arbitrária. A busca por um critério que permitisse a organização de tais dados levou em

9. Segundo os tatuadores, em função da remuneração salarial adicional recebida no período de férias.

10. Comparando-se os dados quantitativos de Fonseca (2003), que são anuais, com minha amostra, que é mensal, observa-se que o estúdio da Tijuca que pesquisei atende mensalmente uma proporção de clientes semelhante a que o estúdio catarinense pesquisado pela autora atende anualmente. consideração a preponderância numérica de casos em determinadas idades, que foram agrupadas. Entre os 16 e 17 anos é possível ser tatuado com a apresentação de uma autorização dos responsáveis. A partir dos 18 anos, construí faixas que possibilitassem tanto uma diferenciação numérica visível ao leitor, quanto a que público é realmente majoritário e em que faixa etária.

$\mathrm{O}$ que se torna mais relevante, ao meu ver, é saber em que medida a tatuagem é hoje uma prática de juventude e em que medida ela tem sido buscada por sujeitos mais velhos. Embora as definições de juventude tenham sido recorrentemente baseadas em uma dicotomia entre a faixa etária e alguns marcos de transiçáo para a idade adulta $^{11}$ (Pais, Cairns e Pappámikail 2005), não

11. São eles: fim do processo de escolarização, primeiro emprego, saída da casa paterna, primeira união conjugal e primeiro filho, com um sentido linear dos acontecimentos que têm se perdido nas últimas décadas em virtude de fatores como novos arranjos con- 
Gráfico n. 2 - Percentuais de clientes no estúdio pesquisado na Zona Norte, nos meses citados, agrupados em dois grupos etários, com corte aos 25 anos.

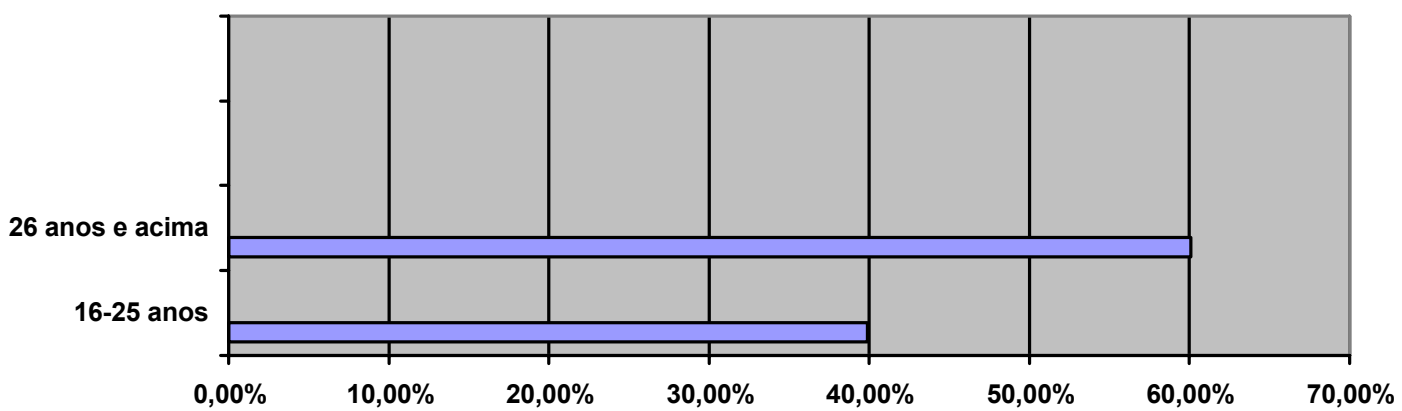

Gráfico n. 3 - Percentuais de clientes no estúdio pesquisado na Zona Norte, nos meses citados, agrupados em dois grupos etários, com corte aos 29 anos.

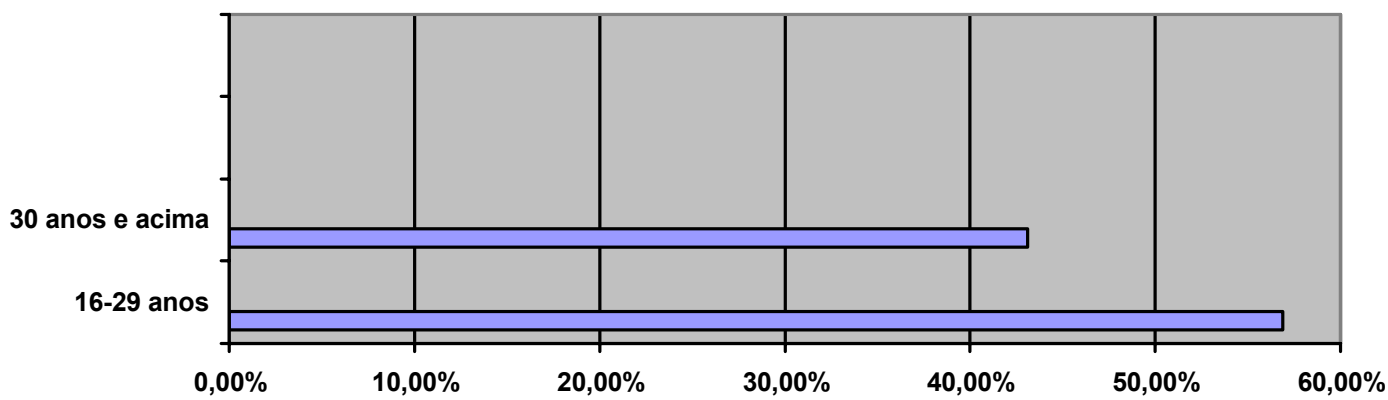

é possível neste trabalho operar a partir destes marcos, uma vez que os dados que permitiram a construção de um perfil de clientes são majoritariamente quantitativos, o que me leva a uma abordagem mais etária e geracional do que dos marcos da transição à idade adulta. Desta forma, agrupei os resultados finais em dois blocos: um que vai dos 16 aos 25 anos e outro que vai dos 26 em diante. Esta escolha se alinha com a indicação etária da OMS sobre o escopo etário da categoria "juventude" como sendo constituído de indivíduos entre 10 e 24 anos, embora alguns autores possam utilizar outro escopo ${ }^{12}$.

Segundo os dados levantados, dos 16 aos 25 anos tem-se um total de 230 clientes $(39,9 \%)$.

jugais, uma nova moral sexual pós-década de 1970, a atual dificuldade de inserção no mercado de trabalho e, conseqüentemente, de estabilidade financeira (Vieira 2006).

12. Pais, Cairns e Pappámikail (2005), por exemplo, para efeitos de pesquisa tomaram a faixa de 16 aos 34 anos.
Acima desta faixa, ou seja, dos 26 em diante, há um total de 349 casos $(60,1 \%)$, conforme pode ser observado no gráfico no 2 . Se o cálculo fosse efetuado com um grupo de 16 aos 29 anos, este total se alteraria para 338 clientes jovens $(56,9 \%)$, contra 250 a partir dos 30 anos $(43,1 \%)$, conforme pode ser observado no gráfico n. ${ }^{\circ} 3$. A faixa entre 26 e 29 anos, portanto, é o diferencial para se definir se a tatuagem é hoje procurada por jovens ou não-jovens.

Pode-se observar na tabela acima que o público preponderante está entre os 20 e os 39 anos, com uma ligeira vantagem para as faixas entre 20 e 25 anos e entre 30 e 39 anos. Esta última faixa é, talvez, aquela que cause alguma surpresa, pois os 30 anos não costumam ser considerados como juventude, muito embora os marcos da passagem à vida adulta venham se tornando tardios, ou seja, sendo alcançados em idades mais avançadas. $\mathrm{O}$ avanço etário da juventude, conforme apontado por diversos autores (Pais, 
Cairns e Pappámikail 2005), envolve dependência financeira, maior tempo residindo na casa paterna/materna, instabilidade profissional no mercado de trabalho, mais anos de escolarização e, para alguns (Singly 1993), relações afetivas instáveis - marcos mais relevantes do que a idade do indivíduo. Outros autores (Lyra et al. 2002) apontam, inclusive, para a criação de novas categorias classificatórias para este fenômeno, como "adultescência", "pós-adolescência" e "geração canguru"13. Para outros, contudo, mais surpreendente pode ser a existência de casos de tatuagem em indivíduos acima dos 60 anos.

Quanto ao gênero, atualmente o público feminino tem sido maioria nos estúdios (Mifflin 1997; Leitão 2002). Em conversas com tatuadores cariocas, a informação foi confirmada. Esta parece ser uma mudança no quadro dos tatuados, pois historicamente a tatuagem ocidental esteve mais ligada ao universo masculino, sobretudo nas figuras dos marinheiros, dos militares e dos criminosos ${ }^{14}$. A partir das fichas de cadastro de clientes preenchidas em um dos estúdios pesquisados, pode-se observar esta maioria feminina, que constitui uma média de $70 \%$ da clientela daquele estúdio ${ }^{15}$.

As tatuagens mais populares entre as mulheres, segundo as fichas de cadastro pesquisadas, seguindo a classificação dos próprios tatuados, são a borboleta $(13,7 \%)$, a estrela $(12,9 \%)$ e a flor $(11,5 \%)$. Evocam valores da feminilidade: frágeis, delicados, pequenos. As tatuagens mais populares entre os homens, segundo as fichas pesquisadas, são os ideogramas japoneses $(14,4 \%)$, as tribais $(11,4 \%)$ e as letras/frase/escrita $(10,6 \%)$.

13. Embora os autores não indiquem o sentido desta última expressão, parece se tratar de uma crítica à saída considerada tardia da casa paterna/materna.

14. Ver Gilbert (2000) e Le Breton (2002), entre outros.

15. Em setembro de 2003, foram 80,2\% de mulheres; em dezembro de 2003, foram 70\%; em janeiro de 2004 , foram $65,5 \%$.
Outra variação quanto ao gênero ${ }^{16}$ é o tamanho da tatuagem: as femininas costumam ser menores do que as masculinas. A região do corpo a ser tatuada também pode diferir entre homens e mulheres, havendo regióes que são preferidas por elas e outras por eles, e ainda algumas tatuadas por ambos. Segundo o levantamento efetuado, as regióes mais tatuadas pelas mulheres são as costas $(26,4 \%)$, seguidas por pescoço/nuca $(23,6 \%)$ e por calcanhar/pé (9,5\%). Entre os homens, o braço emerge como preferido absoluto $(61,7 \%)$, evocando a noção de força física como um valor masculino.

\section{Família, Estado, mercado de trabalho e tatuagem}

Embora o consumidor da tatuagem não seja essencialmente adolescente, estúdios e poder público desenvolveram uma série de restriçóes para o seu atendimento. A partir de agosto de 2004, a Prefeitura do Município do Rio de Janeiro determinou que menores de 16 e 17 anos podem ser tatuados desde que responsáveis assinem um termo de responsabilidade. Apesar das restriçóes e do baixo número de clientes nesta faixa etária (2\%), pode-se encontrar nos próprios estúdios quem tenha feito a primeira tatuagem em idade inferior aos 16 anos.

Em uma tarde de observação na Zona Norte, ouvi a história de Márcia ${ }^{17}$, uma moça de 28 anos, casada, mãe de dois filhos, microempresária. Estava fazendo sua terceira tatuagem. A primeira, contou, fizera aos 13 anos. Já estava desgastada e ela pensava em retirá-la com laser. Não queria retocá-la nem cobrir com outro desenho, pois achava a região tatuada exposta, à mostra com certos tipos de roupa. A tatuagem localizava-se nas costas, perto do ombro. Segundo disse, esteve em um evento com clientes de

16. Para uma reflexão mais aprofundada, ver Osório (2005a) e Osório (2005b).

17. Todos os nomes são fictícios. 
sua empresa e, sentindo calor, retirou o casaco. $\mathrm{O}$ vestido que usava deixava a tatuagem à mostra, o que foi observado por algumas pessoas e automaticamente transformou-se em assunto entre elas. $\mathrm{O}$ comentário que recebeu e reproduziu para mim foi o seguinte: "Nossa, você tem tatuagem? Mas nem parece!”.

A tatuagem executada sobre a adolescente de 13 anos passou a ser vista como um transtorno 15 anos depois em função das exigências do mercado de trabalho, ainda que Márcia não fosse empregada, mas microempresária. $\mathrm{O}$ ato de tatuar-se, contudo, não causou nenhum arrependimento, visto que ela fez mais duas tatuagens. A diferença era, apenas, na escolha da regiáo do corpo: tatuava-se em regióes em que pudesse esconder a marca. O desejo de escondê-la náo é particularidade sua, mas uma preocupação de vários tatuados, sempre em função do mercado de trabalho ${ }^{18}$.

O comentário recebido por Márcia deixa transparecer que a tatuagem não é tão bem aceita quanto se imagina atualmente: não apenas há situaçóes em que ela deve ser escondida, como o fato de ter de sê-lo envolve uma percepçáo real, factual, e não imaginária, de que a tatuagem pode causar transtornos. Uma marca mal-vista no mercado de trabalho, que deve ser escondida, torna-se um adorno charmoso na praia, ou em outras situaçôes, como o flerte, por exemplo (Leitão 2003).

Em outra ocasiáo, antes de serem tornadas públicas as novas determinaçóes municipais sobre o funcionamento dos estúdios, observei um caso correlato no mesmo estúdio. Maria, 16 anos, acompanhada pela máe, queria ser tatuada. O recepcionista encaminhou mãe e filha para que conversassem com o proprietário do estúdio. Este não se recusou a tatuar Maria, argumentando para mim que, se ele se negasse a atendê-la, ela procuraria um outro estúdio ou outro profissional. Em seu estúdio, disse-me,

18. Para maiores considerações, ver Osório (2006). tinha a certeza de que ela seria bem atendida, com profissionais capacitados e material esterilizado. Ao mesmo tempo em que náo queria perder a cliente, ele se preocupava com o que Costa (2004) chamou de biossegurança.

Durante a conversa com Maria, alertou-a que pensasse bem sobre qual desenho gostaria de tatuar e em que parte do corpo. $\mathrm{O}$ ingresso no mercado de trabalho foi o alvo dos alertas sobre o local escolhido. Segundo ele, deveria optar por uma regiáo que náo lhe causasse transtornos futuros. Sobre o desenho, disse que aquela tatuagem seria carregada pelo resto $\mathrm{da}$ vida, que escolhesse algo de que não se arrependesse, pois os gostos da adolescência nem sempre são os mesmos da idade adulta. Neste ponto, a mãe de Maria concordou e disse que a mentalidade da adolescência e os interesses deste período nem sempre acompanham as mudanças da vida. Apenas depois de tantos alertas, perguntou-se a Maria o que ela desejava tatuar: "uma estrela", respondeu. O dono do estúdio relaxou, pois ficou de acordo que era um desenho difícil de causar arrependimento.

$\mathrm{Na}$ medida em que os desenhos escolhidos pelas mulheres, especialmente criados para elas e classificados nos estúdios sob a categoria "desenhos femininos", envolvem representaçóes de feminilidade, estes desenhos são formados por um escopo restrito de possibilidades que envolvem, fundamentalmente, animais e insetos considerados não-agressivos, flores e desenhos infantis, como bonecas, querubins e personagens de gibis e desenhos animados (Meninas Superpoderosas e Hello Kitty, entre outros). Os desenhos infantis são aqueles mais passíveis de causarem "arrependimento", pois se imagina que não farão sentido para o(a) (corpo) adulto(a).

Há uma representação social sobre a adolescência presente nas histórias acima que parece ser um dos fatores de preocupação quanto à tatuagem em menores. $\mathrm{O}$ adolescente - e o jovem de um modo geral - é visto como uma 
força transformadora, mas também como um elemento desordenado e caótico: não pensa no futuro, náo pensa em seu ingresso no mercado de trabalho e por isso pode se arrepender de se tatuar em locais visíveis, ou mesmo de se tatuar; sua mentalidade e interesses podem mudar, pois é um ser incompleto e inexperiente, que viveu poucos anos. Enquanto ele muda e a juventude passa, a tatuagem permanece. Por isso devese pensar bem, escolher com cautela e refletir. Mas, como indica Almeida (2001), mesmo para pós-adolescentes, nem sempre a tatuagem é o resultado de um processo reflexivo.

Segundo Lyra et al. (2002), idéias sobre a adolescência normalmente evolvem concepçôes de crise, desordem, irresponsabilidade e risco (de gravidez, de contágio por HIV, de uso de drogas e de uso/vitimização por violência). Conforme os autores (Lyra et al. 2002: 12), o adolescente é um "sujeito permanentemente em risco, submetido a uma condição especial". $\mathrm{O}$ risco que o adolescente representa a si e à sociedade é o que leva a idéia de prevenção. No caso das tatuagens, esta prevenção tomou a forma de uma ação estatal regulatória.

Embora os cuidados gerados pelo Estado na aplicação de tatuagens em jovens tenham dado aos pais a última palavra sobre o assunto, durante o campo no estúdio da Tijuca não percebi nenhum conflito geracional na escolha pela tatuagem. Nunca ouvi nenhum cliente comentar posiçôes contrárias oriundas da família, a não ser no caso de mulheres adultas com relação a seus maridos. Aqui, a questão da independência financeira feminina como relacionada à sua emancipação se torna bastante visível, bem como a separação entre estas esferas da independência e da autonomia (Vieira 2006).

O caso mais paradigmático, neste sentido, foi o de Cândida, 38 anos, casada, mãe e trabalhando fora de casa em profissão não especificada. Chegou ao estúdio no final da tarde, vinda diretamente de seu trabalho. Havia marcado hora para ser atendida, mas náo havia informado a ninguém de sua família que seria tatuada naquela ocasião. Quando o marido the telefonou para saber onde estava, disse-lhe que seria tatuada em um estúdio. $\mathrm{O}$ marido foi contra. A cena sucedeu da seguinte forma: o marido desligou o telefone; voltou a ligar e Cândida tentou explicar-lhe que era seu o corpo que seria marcado e que ela desejava uma tatuagem; o marido contatou os pais dela que, também contrários, tentaram demovê-la de suas intençóes por telefone; ao final da sessão de telefonemas, ela comentou comigo: "O corpo é meu, o dinheiro é meu, ninguém tem nada a ver com isso. Agora você vê: eu tenho 38 anos e não posso tomar minhas próprias decisóes!”.

Cândida sofreu reprimendas em duas instâncias: como esposa e como filha. No primeiro caso, conquanto participando da "família conjugal moderna”, ou família nuclear, observa-se a força do marido como autoridade, o que faz pensar no que Vaitsman (1994: 33) chamou de "um individualismo patriarcal, legitimando as relaçóes hierárquicas entre homens e mulheres, nas esferas pública e privada". "Aquilo que, realmente e de forma mais evidente, pertence ao indivíduo - seu corpo e seu esforço" (Vaitsman 1994: 28) -, a família de origem e a família nuclear à qual Cândida pertence tentaram simultaneamente roubar-lhe, ou negar-lhe. Sendo esposa, Cândida não cessou de ser filha, ainda sob a vigilância zelosa, embora distante, dos pais.

Entre os clientes mais jovens, todavia, a família não era mencionada. Diversas vezes, na verdade, observei moças jovens comparecerem ao estúdio acompanhadas pelas mães, o que indica uma aceitação da prática, mas também, gostaria de sugerir, sendo uma prática atualmente majoritariamente feminina, tem se tornado parte das práticas femininas de embelezamento e, portanto, um momento passível de ser compartilhado entre mãe e filha. $\mathrm{Na}$ maior parte das vezes, vi as mães aguardarem suas filhas na sala de espera. 
Em alguns casos, a mãe se tornava conselheira, observando o processo de tatuar e interferindo, quando achava necessário. Esta interferência diz respeito, sobretudo, ao que será tatuado (desenho) e onde (local do corpo). De fato, observei que as mães que desempenham este papel de "conselheiras" exercem um controle sobre os corpos de suas filhas. A mãe no estúdio de tatuagem desempenha uma dupla função: ela dá apoio, mas também controla, restringindo a escolha do desenho e do local do corpo a serem tatuados (Osório 2005b).

No caso de adolescentes, a companhia de um dos responsáveis é condição sine qua non para a tatuagem. No estúdio da Zona Sul, os menores não são nem tatuados nem se aplica piercings, mesmo com o acompanhamento de um dos responsáveis. Neste estúdio, observei um caso em que a mãe era contra a tatuagem, mas observei também clientes sendo acompanhadas pelas máes. Nice, cliente na Zona Sul, fez sua primeira tatuagem em janeiro de 2005: o nome de Sáo Judas Tadeu na nuca. Devota do santo, esperava para tatuar sua imagem em outra ocasião, o que realmente ocorreu. $\mathrm{Na}$ época de sua primeira tatuagem morava com a máe, contrária aos desenhos permanentes no corpo, e se afligia em ter que esconder a marca. O irmáo era cliente do estúdio e a havia levado até lá, em companhia de sua noiva, que também seria tatuada. Nice havia escolhido a nuca propositalmente, pois os longos cabelos serviriam para esconder a marca do olhar cuidadoso e vigilante da mãe. Embora o irmáo fosse tatuado, a máe de ambos não poupava críticas à escolha do filho e Nice pretendia fugir às situaçôes de constrangimento materno ocultando a marca. A vigilância e a atenção sobre os filhos permanecem como característica da família (brasileira).

Em reportagem de capa para a revista Vida de agosto de 2004 (Almeida 2004), veiculada semanalmente pelo Jornal do Brasil, em função da Resoluçáo Municipal carioca, o conflito geracional se tornava mais evidente, mesmo que se tratasse do uso do piercing e não da tatuagem. Apresentados na reportagem como grupos geracionais em conflito, percebe-se como os pais faziam uso de percepçóes médicas do corpo para confrontarem os usos que os filhos - jovens - fazem dele. O corpo emerge como o local da disputa e do controle.

Ao longo da reportagem, percebe-se que os pais entrevistados, embora apelem para questóes de "risco à saúde", não estão apenas preocupados com os malefícios físicos que tal prática pode vir a trazer, mas também com as suas implicações morais. Os pais se referem a "problemas", nunca especificados, o que leva a uma idéia de que ou não há argumentos substanciais e a noção de risco está vinculada a um medo difuso ${ }^{19}$, ou se trata de uma alusão a possíveis estigmas (Goffman 1975) tampouco determinados. Observe-se que, na medida em que concepçóes de juventude envolvem a idéia de que os jovens podem romper com códigos morais vigentes mais conservadores e que formam uma espécie de grupo de risco (Lyra et al. 2002), é justamente a implicação moral de seus atos o que preocupa os pais. Se a desconfiança quanto à assepsia e a capacitaçáo do piercer podem ser contornadas com a aplicação da jóia feita por um médico, salvando o jovem dos "riscos à saúde", a desconfiança moral náo pode ser contornada.

$\mathrm{Na}$ revista, apenas adolescentes do sexo feminino foram entrevistadas ${ }^{20}$. Um único rapaz mencionado é primo de uma das entrevistadas, todas menores de 18 anos. Ao final da reportagem, as opinióes de um médico e de um psicólogo dão pistas sobre as diferentes visóes: de

19. Gonçalves (2005), sobre o medo que os pais têm de que seus filhos sejam vítimas da violência urbana, percebe também que o medo é de origem difusa, como se o risco fosse difuso.

20. O estudo dos usos relativos ao piercing não é objeto da pesquisa aqui apresentada, portanto não possuo informaçóes sobre o perfil dos adeptos, sua faixa etária ou gênero majoritário. 
um lado os pais e o discurso médico se alinham em uma voz quase uníssona; de outro, os filhos e o psicólogo apresentam as modificaçóes corporais como fruto da sociedade e da cultura.

A professora Maristella Almeida Cunha, mãe de uma adolescente que fez um piercing aos 13 anos, contou à revista Vida como se preocupou com o que considerou "despreparo para algum imprevisto. Náo havia kit de primeiros socorros, nem um profissional de saúde (...)" (Almeida 2004: 17), apesar de ter considerado o local bastante asséptico. Logo após, ela concluiu: "Não considero o piercing um adorno bonito. Ao contrário, acho vulgar" (Almeida 2004: 17).

O designer gráfico Cláudio Novaes, pai de uma adolescente de 14 anos que teve a jóia colocada em seu umbigo, tinha como argumentos contra a prática "perigos [não especificados] à saúde", o peso de ser uma marca definitiva ${ }^{21}$ no corpo e a imaturidade da filha para cuidar do local perfurado. A solução para as afliçóes do pai zeloso foi procurar um cirurgiáo que colocasse a jóia na menina. A preocupaçáo de Cláudio fora reforçada, segundo a reportagem, por um evento familiar. O primo de sua filha, Daniel Viana, colocara um piercing na língua, aos 17 anos, sem o conhecimento dos responsáveis. Segundo Daniel, o profissional "esterilizou os instrumentos e me mostrou que a agulha era descartável (...)" (Almeida 2004: 19), o que lhe fez confiar no processo. Contudo, segundo a repórter, ele teve "uma leve inflamação no local” (Almeida 2004: 19), o que fez a mãe do rapaz, médica, determinar a retirada da jóia, alegando, segundo Daniel, que ele estava propenso a desenvolver um câncer na língua. $\mathrm{O}$

21. O piercing não é definitivo. Segundo o piercer que trabalhava no estúdio pesquisado na Zona Sul, poucas semanas após a retirada da jóia, independente de quanto tempo ela permaneça no corpo, são suficientes para a oclusão do furo. Contudo, alguma marca pode ser deixada na pele. rapaz argumentou que, sendo fumante, a máe corria mais riscos de ter a doença do que ele.

Vânia Maria de Oliveira, dona-de-casa, negou às filhas de 13 e 16 anos permissão para se submeterem ao piercing. Segundo ela, “isso é só um modismo. Vai passar como todas as modas. Além disso, existem riscos à saúde delas. (...) Se permitisse que elas colocassem o piercing, estaria trazendo problemas para todos nós" (Almeida 2004: 18). A filha de 16 anos argumentou que o piercing pode ser retirado, diferentemente da tatuagem, que é permanente: "Tatuagem, não. É uma marca para sempre” (Almeida 2004: 18). Neste caso, o piercing está em contraposição à tatuagem na percepção adolescente, mas não na materna. Esta diferença é utilizada como argumento para uma prática vista pelos pais não apenas como perigosa, mas como de mau gosto, vulgar, fruto de uma moda que, como todas as modas, há de passar um dia.

Sobre esta categoria, "moda", é interessante observar que a palavra traz em si a idéia de algo passageiro, idéia compartilhada pela filha. Ao mesmo tempo, "moda" ganha um tom pejorativo, de algo que influencia os sujeitos para além de sua capacidade reflexiva e crítica, o que é indicado pela noção de que um piercing poderia trazer problemas a toda a família e não apenas às meninas. Sendo algo passageiro para Vânia, ela não lhe dá valor, prevendo que o tempo dará cabo dos desejos das filhas. A adolescente, contudo, utiliza o mesmo argumento para tentar convencer a mãe de que os eventuais problemas também seriam passageiros, pois a jóia pode ser retirada. Náo creio, contudo, que se tratem dos mesmos "problemas". Quando a adolescente compara tatuagem e piercing, trazendo à tona a diferente natureza das práticas quanto à sua permanência, o que faz é elaborar uma reflexão sobre elas. Ela se coloca em posiçáo desprivilegiada para decidir sobre algo que pode marcá-la por toda a vida, como a tatuagem, mas não para decidir sobre o piercing, por sua qualidade não-permanente. 
No conflito de geraçóes, são noções morais de gosto (o vulgar e o modismo, por exemplo) que parecem exprimir os prós e contras para piercings e tatuagens - e possivelmente outras práticas de modificação corporal, mas gostaria de sugerir que o que está em jogo é, de fato, o grau de autonomia dado ou negado aos filhos. Quando o gosto adolescente e o gosto paterno entram em conflito (no caso paterno, relacionado a questóes morais), lança-se mão dos "riscos à saúde" para coibir as intençóes dos mais jovens. Em sujeitos acima desta faixa etária, não há como proibir a prática, mas a atuação repressiva da família opera mais diretamente com as noçóes de gosto e de risco, como que escondendo por trás do embate a questáo central da autonomia.

Não se trata, aqui, de negar a preocupação dos pais quanto ao bem-estar de sua prole, nem tampouco observar seu papel exclusivamente sob a ótica da imposição de limites. Pelo contrário, apontei neste trabalho como as mães, especialmente, podem apoiar as filhas na decisão de adquirir uma tatuagem. $\mathrm{O}$ que a reportagem apresenta é uma visão que os pais têm da juventude e de modificaçóes corporais que se tornaram populares recentemente, tanto quanto de seu próprio papel regulatório como pais, cuidando tanto da saúde quanto do comportamento moral de seus filhos. Este papel da família não é recente, mas é um produto das transformaçóes sociais entre os séculos XVIII e XIX na Europa, popularizadas nos preceitos higienistas (Donzelot 1986).

Um cliente do estúdio pesquisado na Zona Sul, Francisco, indicou como viveu o processo familiar contrário à tatuagem. Morando sozinho desde seus 19 anos, tatuou-se sem o conhecimento de seus pais. $\mathrm{O}$ desenho gravado no braço era escondido pelas mangas de camisa. Quando se tornou mais confiante de seu desejo por novas marcas, Francisco tornou-se, ao mesmo tempo, mais relaxado no encobrimento da tatuagem. A mãe, ao perceber o desenho, disse-lhe que era bonito, mas que esperava que fosse o único. A cada nova tatuagem, contou ele, a mãe reforça o desejo de que não se tatue mais. Seu pai, por outro lado, foi mais enfático na crítica ao filho: disse-lhe que "quem pinta o corpo é índio", indicando a velha diferenciação entre hábitos civilizados, de bom gosto, e hábitos selvagens, que devem ser evitados.

Moda ou "coisa de índio", trata-se de algo que não nos pertence e que, por isso, deve ser abandonado. Trata-se, justamente, de uma diferença cultural. $\mathrm{O}$ pai do cliente observa a prática como culturalmente mais alinhada com outros povos, operando uma desvalorização da mesma. É justamente nesta falta de percepção da tatuagem como uma nova prática corporal, alinhada com uma nova cultura do corpo, que os pais de adolescentes encontram argumentos para se oporem aos piercings, desvalorizando-os a partir da noção de que se trata de uma moda. Tenho sugerido aqui, contudo, que se trata menos de uma questão de "gosto" ou de "risco" do que da percepção da família de que se tatuar é uma forma de exprimir individualidade e que o piercing constitui, neste processo de individualização e exercício de autonomia, espécie de meio caminho andado.

\section{Mudança de status}

Em outras ocasióes, vi meninas com os recém-completos 18 anos irem ao estúdio para serem tatuadas. Mônica foi ao estúdio da Tijuca para se dar de presente de aniversário, como contou, sua primeira tatuagem. Havia atingido à maioridade três dias antes. $\mathrm{O}$ namorado foi acompanhá-la na aventura. Escolhera tatuar um leão por ser o seu signo astrológico. $\mathrm{O}$ tatuador escolheu um leão filhote como modelo e teve a preocupação de torná-lo "um desenho feminino", conforme disse a Mônica, ou seja, sem traços de agressividade. A moça escolheu a panturrilha como local a ser marcado, na parte lateral, um pouco acima do tornozelo. 
Marcela, por sua vez, fora para sua primeira tatuagem acompanhada por uma amiga de cerca de 35 anos, que já possuía algumas. $\mathrm{O}$ desenho era um presente de aniversário, cujo valor seria dividido entre as duas. Escolheu um gnomo sentado em um cogumelo, mas pediu ao tatuador que diminuísse o desenho. Escolheu as costas (omoplata) para tatuá-lo, mesmo local em que Márcia fizera sua primeira tatuagem.

A panturrilha que Mônica escolheu tatuar é um local tão visível quanto as costas onde Márcia e Marcela fizeram suas primeiras tatuagens. Sendo a tatuagem um adorno corporal, que o tatuado entende como uma espécie de embelezamento de seu corpo, convém perguntar se a primeira marca não é escolhida justamente em algum lugar de fácil visibilidade, para que esteja à mostra, identificando o antes não tatuado a um agora-tatuado. A idéia de ser tatuado pode envolver noçóes de que o tatuado é uma pessoa alheia às imposições sociais ${ }^{22}$, que tem personalidade para ir contra elas - o que de fato nem sempre ocorre, dada a preocupação em poder esconder os desenhos -, de que é autêntico e original. Ao mesmo tempo em que a panturrilha de Mônica e as costas de Márcia e Marcela podem ser facilmente deixadas à mostra, também podem ser escondidas pelas roupas. Márcia, contudo, não viu muita praticidade em ter que esconder sua primeira tatuagem, em um local mal escolhido segundo sua visão atual.

Para Marcela e Mônica, os 18 anos foram marcados pela idéia de liberdade: a liberdade de se tatuarem, a autonomia sobre seus corpos, a liberdade de fazerem dele o que quisessem, sem a presença de nenhum responsável, mas com o apoio de uma amiga ou um namorado. $\mathrm{Ou}$ seja, liberdade e autonomia, mas náo isolamento. Ambas pareciam igualmente realizadas por passarem por aquele processo, como se ele fosse a prova, espécie de marca de uma mudança de

22. Posiçôes contrárias oriundas da família e do mercado de trabalho, entre outros. status, que mostra ao mundo este novo status recém-adquirido. Muito mais do que tatuadas, estavam informando, por meio de seus corpos, que eram pessoas "maiores", ou seja, com um grau de autonomia antes inexistente.

Ao invés de um isolamento no ato de serem tatuadas, apresentaram uma sociabilidade intrageracional, como que marcando, além do corpo, uma prática associada ao indivíduo e náo a processos coletivos. Torna-se interessante, aqui, diferenciar esta situação daquela na qual a mãe acompanha a filha, quando a relação intergeracional marca um processo coletivo feminino de práticas corporais e não necessariamente um rompimento com um status de menoridade. Convém questionar, aqui, o quanto a companhia do responsável freia a sensação de autonomia em adolescentes de 16 e 17 anos que desejam ser tatuados. Por outro lado, alguns autores têm apontado para a relevância do apoio familiar no cotidiano de jovens que não residem mais com suas famílias, casados ou não (Singly 1993). Se a família apóia a emancipação, pode perfeitamente bem apoiar a tatuagem, respeitando a escolha do adolescente, seja ela encarada como uma busca pelo exercício de autonomia ou não.

A tatuagem como marca de mudança de status não é exclusividade dos jovens. No estúdio pesquisado na Zona Sul, observei Nice, já recémcasada, adquirir tatuagens após a saída da casa materna e da mudança de seu status de solteira para casada (uma das tatuagens era o nome do marido). Em outra ocasião, conheci um senhor recentemente aposentado que fazia sua primeira tatuagem com o significado, segundo ele, de um recomeço em sua vida, portanto marcando igualmente uma mudança de status.

Estes casos ensejam uma idéia de tatuagem como rito de passagem (Van Gennep 1978). $\mathrm{O}$ rito, porém, não parece ser constituído pelo processo de ser tatuado, mas ostentar a tatuagem pode se tornar uma forma de marcar esta mudança de status. Conforme Van Gennep 
(1978), a marca corporal faz parte de alguns destes ritos ${ }^{23}$. Os ritos de passagem são formados por três estágios, por assim dizer: separação, margem e agregação. A marca corporal, neste contexto, é a marca de agregação. No caso dos 18 anos recém-completos, de agregação ao universo da maioridade.

\section{Autonomia, corpo, individualismo e posse de si}

$\mathrm{O}$ individualismo na juventude incorre em elementos como o valor dado à autonomia, à diversão e à experimentação, bem como às idéias de escolha, auto-realização e autenticidade (Pais, Cairns e Pappámikail 2005). No caso da tatuagem, é necessária uma leitura conjunta sobre individualismo e usos do corpo. Em meu argumento, a tatuagem entre alguns jovens tanto quanto entre algumas mulheres - embora aqui eu tenha privilegiado os primeiros como foco da análise - expressa uma busca, ou um exercício, de autonomia pessoal, conceito relacionado, conforme visto, ao de individualismo e de experimentação. $\mathrm{O}$ corpo pode ser, nestes casos, um dos espaços desta experimentação tanto quanto da marca desta autonomia. A auto-realização, a experimentação e a autonomia passam pelos usos que o sujeito faz de seu corpo.

Observei em campo uma visão dos tatuadores que opóe modismo e originalidade. Esta é mais valorizada do que aquele. Embora se trate de uma oposição que se refere aos desenhos escolhidos e à natureza desta escolha (desenhos "da moda" versus desenhos cujo significado é pessoal $)^{24}$, pode-se muito bem ampliar esta visão identificando na própria marca a conferência de um status positivo, do ponto de vista do tatuado, no sentido de que lhe confere origina-

23. Para exemplos concretos ver Borel (1992) e Gell (1993).

24. Pessoalmente atribuído ao desenho ou a uma fase de vida que o tatuado diz que o desenho representa. lidade, associada a uma noção de individualidade. Não se trata, necessariamente, de observar a tatuagem como expressão de um Eu interior, de uma identidade que aflora na pele. A escolha de desenhos cujos significados são pessoais denota, ao contrário, um uso reflexivo da escolha, amparado de certa forma em escolhas racionais. Originalidade e autenticidade não são sinônimos. Um desenho original é aquele sem cópia, ou seja, individual, que ninguém mais possui. Ele distingue seu portador. Autenticidade é uma noção que remete à idéia de uma identidade latente, conforme Singly (1996).

A tatuagem relacionada à autonomia foi caracterizada na literatura dedicada ao estudo das tatuagens sob o conceito de posse de si (Benson 2000; Le Breton 2002), segundo o qual os tatuados marcam seu corpo como uma forma de afirmação de propriedade sobre ele. Noção amparada em um contexto individualista, em que a autonomia pessoal é valorizada e buscada, traz questóes relacionadas à dinâmica entre indivíduo e sociedade, mas também controle e resistência, superfície e profundidade e, ainda, corpo/mente (Eu interior).

Para Benson (2000), é em um contexto individualista ocidental que a tatuagem passa a adquirir este uso de posse de si, identificando o corpo não mais como um objeto e sim como pertencente ao $\mathrm{Eu}$, ao sujeito. Trata-se de uma marca que emerge à superfície vinda das profundezas do $\mathrm{Eu}$, em uma espécie de grito por autonomia.

Para Le Breton (2002), o conceito é percebido na disputa geracional entre jovens e pais. A disputa pelo controle daqueles, que passa pelo controle de seus corpos, faz com que busquem na tatuagem uma forma de marcar o pertencimento de seus corpos a si mesmos, e não mais a seus pais. Diz o autor: "os corpos legados pelos parentes são modificados para se fazerem definitivamente seus [dos jovens]"25 (Le Breton 2002: 172). "A marca corporal assinala o per-

25. "Les corps légué par les parents est à modifier pour le faire défnitivement sien". 
tencimento a si. Rito pessoal para se transformar transformando a forma de seu corpo" ${ }^{26}$ (Le Breton 2002: 175).

A marca dá posse ao corpo, uma posse requisitada pelo sujeito frente a determinadas instâncias (controladoras) da sociedade. No caso dos jovens, esta instância é a família e é compreensível que o seja, uma vez que a saída da casa paterna/materna e a independência financeira constituem marcos da transição para a idade adulta e, conseqüentemente, de independência e ganho de autonomia. Assim, ao mesmo tempo em que marca a mudança de status, atesta o tomar posse de seu corpo como uma forma de autonomia pessoal.

O mercado de trabalho, por outro lado, é uma instância reguladora cujo poder não pode ser questionado, tampouco o é. Em campo, observou-se todo um processo de racionalização na escolha dos locais a serem tatuados, em função não apenas da família, mas sobretudo do mercado de trabalho. Este aceita os tatuados apenas na medida em que suas tatuagens possam ser consideradas discretas, o que na maior parte das vezes significa pequenas ${ }^{27}$ e cobertas, conforme reportagem de Calaza (2005) para o jornal $O$ Globo demonstrou.

Contudo, conforme vem sendo apontado pela literatura dedicada ao tema das tatuagens, hoje as mulheres constituem a clientela majoritária da prática. Assim, pode-se sugerir aqui, também, que a tatuagem como signo de autonomia opera dicotomicamente tanto em termos geracionais quanto em termos de gêne-

26. "La marque corporelle signe l'appartenance à soi. Rite personnel pour se changer soi em changeant la forme de son corps".

27. Daí, provavelmente como mais uma variável na construção desse novo público da tatuagem, a grande procura feminina por tatuagens: suas áreas do corpo tatuadas e seus desenhos são sempre pequenos $\mathrm{e}$ o jogo de revelar/esconder é utilizado por elas em aspectos outros que não o profissional, tais como o flerte e a sedução. Ver Leitão (2002). ro. Em outras palavras, os jovens aos quais me refiro no presente artigo são, em sua maioria, as jovens. Dadas as relaçóes de gênero no Brasil, onde uma igualdade entre os sexos não foi alcançada, pode-se propor que, para elas, alcançar uma autonomia tem um sentido particular, na medida em que as moças costumam ser mais controladas do que os rapazes. De fato, a pesquisa de campo apontou para um constrangimento sofrido por algumas mulheres adultas (economicamente ativas, casadas e mães) ao fazerem suas tatuagens, constrangimento este causado tanto pela família de origem quanto pelo marido/namorado/companheiro. O controle dos corpos femininos é exercido de uma forma que não se opera sobre os homens (Bourdieu 2003) e este controle é uma das principais formas de controle dos sujeitos.

Autoridade, autonomia e controle corporal são questóes relacionadas que se tornam explícitas em contextos de punição física ${ }^{28} \mathrm{e}$ marcação punitiva. Em qualquer caso de marcação punitiva, o que está em jogo é o poder de controle da autoridade que pune sobre o indivíduo. A marcação é um meio de estigmatizar e identificar (Anderson 2000). Se ela é permanente, significa que a identidade atribuída por meio da marca também é pensada como permanente por aquele que a produz. Gustafson (2000) afirma que a marca ${ }^{29}$ é envolta em um processo pedagógico que visa alterar a mentalidade, a noção de si e o poder pessoal. Logo, a marca auto-imposta pode funcionar de igual

28. Gonçalves (2005) chama a atenção para o uso da punição física de crianças e jovens de classes populares por seus pais, especialmente as mães, que, segundo a autora, defendem tais métodos vistos por elas como educativos, crendo que são capazes de forjar o bom caráter, apontando para um caminho de retidão moral. Embora não se possa afirmar que o público pesquisado tenha sido educado desta forma pela família, fica o registro de que a família pode utilizar a força física como punição.

29. Tatuagem e branding (marca a ferro quente). 
forma, alterando a mentalidade e a noção que o sujeito tem de si, bem como seu poder pessoal. Neste caso, sugiro um aumento desse poder e a formação de uma percepção de autonomia pessoal. O corpo pode ser marcado como propriedade alheia ou como propriedade do Eu. Ele torna aparente uma condição social, isto é, torna visível, através de símbolos, o status social do sujeito.

A análise de Foucault (1997) aponta claramente para esta tensão inscrita no corpo, pois ele é o limite entre o $\mathrm{Eu}$ (mental individual) e o Mundo (social) ${ }^{30}$. No corpo, a pele se apresenta como o limite extremo (Gell 1993), que toca a esfera interna (do indivíduo) e externa (do mundo). Sendo o limite, pode-se sugerir que é sua região mais sensível, onde as lutas entre controle e autonomia se dão mais fortemente e as marcas de um e de outro são dispostas como troféus.

\section{Consideraçóes Finais}

Rompendo com um senso comum que pensa a tatuagem como um adorno corporal utilizado por indivíduos do sexo masculino participantes de grupos jovens, observei, em campo, que o público atual da prática é outro e que seu uso vai além do embelezamento. $\mathrm{O}$ universo da tatuagem, conforme indicado de forma rápida, é generificado, ou seja, constituído por separações entre os gêneros. Embora não haja uma separação análoga baseada nas categorias adulto e jovem, a geração e a faixa etária parecem apresentar distinçóes interessantes quanto aos usos. Entre estes usos, destaquei aqueles observados entre os jovens, mas não necessariamente exclusivos deles.

30. Basicamente em contexto moderno-individualista, pois, como apontam o próprio Foucault (1997) e também Rodrigues (2001), em contexto pré-moderno não há esta construção individualista do corpo e seus usos e percepçóes são distintos.
Foi apenas a partir de uma visáo dada pelo trabalho de campo que se pôde constituir algumas das idéias aqui apresentadas. Em primeiro lugar, a tatuagem não é um adorno caracteristicamente jovem, mas é popular entre os jovens. Em segundo lugar, coube observar em que situaçóes a juventude foi um fator associado à prática. A partir destes dois eixos, então, identifiquei casos em que a marca envolve a mudança de status e outras situaçóes em que ela se apresenta em meio a um conflito ou tensáo pelo poder de modificar o próprio corpo. Em ambos os casos, há um uso político do corpo acenando para as relações de poder existentes no cotidiano dos sujeitos. Estas relações são mantidas especialmente em duas esferas: na família e no mercado de trabalho.

Utilizando a restrição ao uso de piercings como um contraponto, indiquei como a permanência da marca nem sempre é a questáochave quanto à interdição de seu uso. Em outras palavras, as restriçóes impostas aos adolescentes que querem um piercing parecem ser da mesma natureza que aquelas impostas sobre quem deseja uma tatuagem e é constrangido pelo poder público ou pela própria família. Na busca pelo direito à marca, então, os tatuados empreendem uma busca pelo poder de modificar seus corpos. A autonomia sobre o corpo é uma autonomia sobre o indivíduo. Trata-se, portanto, de uma marca que, mais que um adorno, enseja uma reflexão sobre liberdade, controle e resistência.

Sobre os jovens observados em campo, está clara a relaçáo entre maioridade e autonomia como causas de uma mudança de status. Entre outros jovens, possivelmente, a autonomia não é o fator determinante da aquisição da marca, com isso apontando para a autonomia como necessidade de alguns, não de todos, e para a tatuagem como processo que marca esta autonomia para alguns, mas não para todos. Existem múltiplos usos possíveis para a tatuagem, incluindo aqueles relativos ao embelezamento e à sedução. 
Náo coube tratar de cada um deles, mas indicar um caminho reflexivo para se compreender sua importância e seu uso entre os jovens.

Os embates percebidos na aceitação ou não da tatuagem e no desejo por ela não são oriundos do próprio universo da tatuagem, mas reflexo da sociedade, das relaçóes familiares e da inserção dos indivíduos no mercado de trabalho, seu imaginário e suas aspiraçóes. Assim, o corpo e em especial a tatuagem permitem uma reflexão sobre instâncias de controle do indivíduo que são instâncias de controle corporal, bem como a relação que este indivíduo pode manter com tais instâncias. $\mathrm{O}$ corpo emerge como espaço de uma luta simbólica, política, por individualidade. Nesta luta, autonomia, originalidade, distinção, liberdade, controle e resistência são elementos constitutivos do processo experimentado: em alguns casos causa, em outros conseqüência do desejo de ser tatuado.

\section{Tattoos and autonomy: reflections about youth}

abstract Research carried through in two tattoo studios in the city of Rio de Janeiro pointed to the predominance of customers between 20 to the 29 years. About $60 \%$ of the public of one of these studios is formed by customers between 16 and 29 years. As a background of the seduction that tattoos exerts on youth, it seems to be a process of social marking - on the body - of personal autonomy, that was nominated in the literature dedicated to the study of the contemporary tattoos as self possession. It is a concept related to the emergency of an individualization process, where tattoos can be presented as a propitious sign of a personal (and social) proof of force and courage, or as a quiet rebellion against instances of individual, specially the family.

keywords Tattoo. Youth. Autonomy.

\section{Referências bibliográficas}

ABRAMO, Helena. 1994. Cenas juvenis - punks e darks no espetáculo urbano. São Paulo: Scritta.

ALMEIDA, Maria Isabel Mendes de. 2001. "Nada além da epiderme: a performance romântica da tatuagem". Psicologia Clínica, 12 (2): 103-123.

ALMEIDA, Aline. 2004. "No ringue com o piercing - a moda do adereço perfurante divide os pais, que temem pela saúde dos filhos." Revista Vida do Jornal do Brasil, ano 1, n. 36: 16-20, 14 ago.

ANDERSON, Clare. 2000. "Godna: inscribing indian convicts in the nineteenth century" In Jane Caplan (org.), Written on the body - the tattoo in european and american history. New Jersey: Princeton University Press, pp-102-117.

BENSON, Susan. 2000. "Inscriptions of the Self: reflections on tattooing and piercing in contemporary Euro-America." In Jane Caplan (org.), Written on the body - the tattoo in european and american history. New Jersey: Princeton University Press.

BOREL, France. 1992. Le vêtement incarné - les métamorphoses du corps. Paris: Calmann-Lévy.

BOURDIEU, Pierre. [1998] A dominação masculina. Rio de Janeiro: Bertrand, 2003.

CAIAFA, Janice. [1985] Movimento punk na cidade - a invasão dos bandos sub. Rio de Janeiro: Zahar, 1988.

CALAZA, Luciana. 2005. "Com o dragão tatuado no braço - aumento do número de pessoas com tatuagem e piercing gera polêmica no mercado de trabalho.” $O$ Globo. Boa Chance: $1.1^{\circ}$ maio.

COSTA, Márcia Regina. 1993. Os 'carecas do subúrbio'caminhos de um nomadismo moderno. Petrópolis: Vozes.

COSTA, Zeila. 2004. Do porão ao estúdio - trajetórias e práticas de tatuadores e transformaçóes no universo da tatuagem. Dissertação de Mestrado. Florianópolis: Universidade Federal de Santa Catarina, datilo.

DONZELOT, Jacques. [1980] A polícia das famílias. Rio de Janeiro: Graal, 1986.

FONSECA, Andrea Lisset Perez. 2003. Tatuar e ser tatuado - etnografia da prática contemporânea da tatuagem, estúdio: Experience Art tattoo - Florianópolis - SC. Dissertação de Mestrado. Florianópolis: Universidade Federal de Santa Catarina, datilo.

FOUCAULT, Michel. [1975]. Vigiar e punir. Petrópolis: Editora Vozes, 1997.

GELL, Alfred. 1993. Wrapping in images - tattooing in Polynesia. Oxford: Clarendon Press.

GILBERT, Steve. 2000. Tattoo history - a source book. New York: Juno Books. 
GOFFMAN, Erving. [1963] Estigma - notas sobre a manipulaçâo da identidade deteriorada. Rio de Janeiro: Zahar Editores, 1975.

GONÇALVES, Hebe Signorini. 2005. "Juventude brasileira, entre a tradição e a modernidade”. Tempo Social, v. 17, n. 2, novembro/2005: 207-219.

GUSTAFSON, Mark. 2000. "The tattoo in the later roman empire and beyond" In Jane Caplan (org.), Written on the body - the tattoo in european and american history. New Jersey: Princeton.

LE BRETON, David. 2002. Signes d'identité - tatouages, piercings et autres marques corporelles. Paris: Métaillé.

LEAL, Mariana. 2005. "Pele ilustrada". In Beleza pura. Espelho meu. Disponível em: <http://www.belezapura.org.br>. Acesso em: 17 fev. 2005.

LEITÃO, Débora Krischke. 2002. O corpo ilustrado - um estudo antropológico sobre usos e significados da tatuagem contemporânea. Dissertação de Mestrado. Porto Alegre: Universidade Federal do Rio Grande do Sul, datilo.

LYRA, Jorge et al. 2002. "'A gente não pode fazer nada, só podemos decidir sabor de sorvete'. Adolescentes: de sujeito de necessidades a um sujeito de direitos". Caderno Cedes, v. 22, n. 57, agosto/2002: 9-21.

MARQUES, Toni. 1997. O Brasil tatuado e outros mundos. Rio de Janeiro: Rocco.

OSÓRIO, Andréa. 2005a. "O frouxo e o carniceiro: dor e concepçóes de gênero em dois estúdios de tatuagem cariocas”. Revista Gênero, v. 5, n. 2, 1. sem. 2005: 113135.

2005b. "O gênero da tatuagem: pensando masculino e feminino em estúdios no Rio de Janeiro". Revista Contemporânea, ano III, n. 5, dezembro/2005. Disponível em: <http://www2.uerj.br/ffcs/contemporanea/n5/artigosorio.htm>. Acesso em: 20 jun. 2006.

\section{autor Andréa Osório}

Doutora em Antropologia / UFRJ

\author{
Recebido em 10/02/2006 \\ Aceito para publicação em 01/07/2006
}

2006. O gênero da tatuagem - continuidades e novos usos relativos à prática na cidade do Rio de Janeiro. Tese de Doutorado. Rio de Janeiro: IFCS-UFRJ, datilo.

PAIS, José Machado; CAIRNS, David; PAPPÁMIKAIL, Lia. 2005. "Jovens europeus: retrato da diversidade". Tempo Social, v. 17, n. 2, novembro/2005: 109-140.

RIO DE JANEIRO (Município). 2004. Secretaria Municipal de Governo. "Resolução SMG ”N" n. 690 de 30 de julho de 2004. Dispóe sobre a regulamentação para o funcionamento dos estabelecimentos executores da atividade de interesse à saúde em aplicação de piercing e tatuagem, e dá outras providências.” Diário Oficial Eletrônico do Município. Disponível em: < http://www. rio.rj.gov.br/dorio >. Acesso em: 30 ago. 2004.

RODRIGUES, José Carlos. 2001. O corpo na história. Rio de Janeiro: Fiocruz.

SINGLY, François de. 1993. Sociologie da la famille contemporaine. Paris: Nathan.

1996. Le soi, le couple et la famille. Paris: Nathan.

VAITSMAN, Jeni. 1994. Flexiveis e plurais - identidade, casamento e familia em circunstâncias pós-modernas. Rio de Janeiro: Rocco.

VAN GENNEP, Arnold. [1909] Os ritos de passagem. Petrópolis: Vozes, 1978.

VIANNA, Hermano. 1985. O mundo funk carioca. Rio de Janeiro: Zahar.

VIEIRA, Joice Melo. 2006. "Transição para a vida adulta, família e curso de vida”. XXV Reunião Brasileira de Antropologia. CD-Room.

WELLER, Wivian. 2005. "A presença feminina nas (sub)culturas juvenis: a arte de se tornar visível”. Revista Estudos Feministas, 13(1), janeiro-abril/2005: 107-126. 